\title{
Exceptional grain refinement in a Mg alloy during high pressure torsion due to rare earth containing nanosized precipitates
}

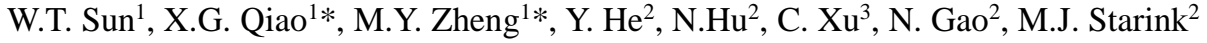 \\ ${ }^{1}$ School of Materials Science and Engineering, Harbin Institute of Technology, Harbin 150001, PR China \\ ${ }^{2}$ Materials Research Group, Faculty of Engineering and the Environment, University of Southampton, Southampton \\ SO17 1BJ, UK \\ ${ }^{3}$ Department of Mechanical Engineering, Nagaoka University of Technology, Nagaoka 940-2188, Japan \\ * zhenghe@ @it.edu.cn, Tel.: +8645186402291, fax: +8645186413922 \\ *xgqiao@ hit.edu.cn, Tel.: +86451 86402291, fax: +8645186413922
}

\begin{abstract}
:
The influence of the nanosized rare earth $(\mathrm{RE})$ containing precipitates on grain refinement during severe plastic deformation is investigated in detail through a study of high pressure torsion (HPT) processing of a solution treated and aged $\mathrm{Mg}-8.2 \mathrm{Gd}-3.8 \mathrm{Y}-1.0 \mathrm{Zn}-0.4 \mathrm{Zr}$ (wt.\%). In the early stages of HPT deformation, dislocation generation and pile-up is promoted by the nanosized RE containing $\beta^{\prime}$ precipitates. With increasing strain, the precipitates are cut by the moving dislocations and gradually dissolve into the $\alpha-\mathrm{Mg}$ matrix aided by dislocations serving as diffusion channels for solute atoms. After HPT for 2 turns, the hardness reaches a maximum and on further deformation the microhardness decreases although the microstructure refinement continues and the dislocation density is increasing. This is due to the continuing dissolution of precipitates, which dominates the hardness evolution at this stage. After HPT for 16 turns, the precipitates have almost completely dissolved and the average grain size is $\sim 33 \mathrm{~nm}$, which is the smallest ever reported for a Mg- or Al-based alloy. The present peak-aged Mg-8.2Gd-3.8Y-1.0Zn-0.4Zr (wt.\%) alloy exhibits quite different microstructure evolution and hardening behaviour during HPT processing as compared to both the cast and the solutionized Mg-Gd-Y-Zn-Zr alloy.
\end{abstract}

Key words: Mg-RE alloy; High pressure torsion; Precipitates; Microstructure evolution; Work hardening.

\section{Introduction}

Magnesium alloys are promising lightweight structural materials $[1,2]$ and in recent years, special attention has been paid to high-strength $\mathrm{Mg}$ alloys containing rare earth (RE) elements, because the RE addition causes significant solution hardening and precipitation hardening [3, 4]. Solution treatment and ageing of Mg-Gd-Y-Zn-Zr alloys can produce a dense distribution of fine $\beta^{\prime}$ phase precipitates inside the grains, which impedes the mobility of the dislocations effectively, leading to a remarkable strength improvement [5-8].

The yield strength of metallic alloys can be improved by grain refinement $[9,10]$, and severe 
plastic deformation (SPD) has been identified as a potential technique to fabricate metals with submicrometer or even nanoscale grain structure [11]. However, for pure metals with melting temperatures below $1100 \mathrm{~K}$, like $\mathrm{Mg}$, grain refinement obtained by SPD at room temperature is limited to about $1 \mu \mathrm{m}$, and for most conventional $\mathrm{Mg}$ alloys grain refinement achieved by SPD is limited to about $100 \mathrm{~nm}$.

Our motivation for the present work lies in a quest to obtain exceptionally refined microstructures in light alloys. It is considered that an interaction between nanosized RE containing particles with high numbers of moving dislocations generated by SPD combined with particle-stimulated nucleation (PSN) of grains may provide such exceptional refinement. In this work we use high pressure torsion (HPT), as it is considered the most effective way to produce high shear strains combined with a high hydrostatic pressure of several GPa [12-14]. There are very few reports on HPT of aged Mg-RE alloys containing fine precipitates. A recent work on HPT processing of an aged Mg-9.4Dy2.0Al-0.7Zn-0.2Zr (wt.\%) alloy indicated that the effect of prior ageing on microhardness enhancement by HPT was limited: the alloy's hardness was found to be $\sim 94 \mathrm{HV}$ after solution-treatment + HPT, 105 HV after $250{ }^{\circ} \mathrm{C}$-age $+\mathrm{HPT}$ and $\sim 100 \mathrm{HV}$ after $300{ }^{\circ} \mathrm{C}$-age + HPT) [15]. However, in that recent study on $\mathrm{Mg}$ 9.4Dy-2.0Al-0.7Zn-0.2Zr only three HPT revolutions were applied, whilst the RE content was limited to only Dy. Thus a further study incorporating the influence of strain (i.e. by increasing the number of HPT turns) on precipitation evolution and mechanical properties is needed, and an also the influence of an increased RE content needs further study.

In the present study, peak-aged Mg-8.2Gd-3.8Y$1.0 \mathrm{Zn}-0.4 \mathrm{Zr} \quad$ (wt.\%) alloy samples containing nanosized $\beta^{\prime}$ precipitates are processed by HPT up to 16 turns to examine the evolution of the nanosized precipitates during HPT processing and to explore the phase transformation on the microstructure refinement and mechanical performance.

\section{Experimental procedures}

The Mg-8.2Gd-3.8Y-1.0Zn-0.4Zr (wt.\%) alloy ingot was fabricated by direct-chill casting, the details are presented in [16]. Specimens machined from the ingot were solution heat treated at $510{ }^{\circ} \mathrm{C}$ for $12 \mathrm{~h}$ followed by water quenching, and these specimens were subsequently subjected to an ageing treatment at $200{ }^{\circ} \mathrm{C}$ for $48 \mathrm{~h}$ followed by water quenching [5]. During this ageing the hardness increased from $88 \pm 5$ $\mathrm{HV}$ to $114 \pm 3 \mathrm{HV}$, which represents the peak hardness for this conventional T6 type heat treatment. The peakaged material was machined into disks with diameter of $10.0 \mathrm{~mm}$ and thickness of $1.0 \mathrm{~mm}$, which were ground using abrasive papers on both sides to final thickness of $\sim 0.85 \mathrm{~mm}$ (see Fig. 1(a)). The disks were deformed by HPT at ambient temperature under quasiconstrained conditions [12, 17] through various numbers of rotational turns, i.e. $1 / 8,1,2,10$ and 16 turns, using an imposed pressure of $6.0 \mathrm{GPa}$ with the lower anvil rotating at $1 \mathrm{rpm}$ (see Fig. 1(b)).

The microstructure of the peak-aged specimens before and after HPT processing was studied by a FEITecnaiG ${ }^{2}$ F30 transmission electron microscope (TEM) operating at $300 \mathrm{kV}$. To obtain TEM samples, disks of $3 \mathrm{~mm}$ in diameter were punched out from the HPTprocessed disks at the half-radius position, and subsequently these samples were mechanically polished and ion-beam milled using a Gatan plasma ion polisher. The average grain sizes of different HPTprocessed samples were measured from 15 TEM images in 15 random selected areas using the modified line intercept method [18-20].

$\mathrm{X}$-ray diffraction (XRD) was performed using an $X$ ' Pert PRO X-ray diffractometer using $\mathrm{Cu} \mathrm{Ka}$ radiation. To determine the microstrains $\left\langle\varepsilon^{2}\right\rangle^{1 / 2}$ and crystallite sizes $D c, \mathrm{XRD}$ line broadening analysis was 
performed using the Materials Analysis using Diffraction (MAUD) software. Details of this method have been described elsewhere $[20,21]$. The dislocation density $\rho$ was estimated by the following equation $[20,22,23]$ :

$$
\rho=\frac{2 \sqrt{3}\left\langle\varepsilon^{2}\right\rangle^{1 / 2}}{D_{c} b}
$$

where $b$ is the Burgers vector.

After HPT processing, each disk was carefully ground to 4000-grid $\mathrm{SiC}$ abrasive paper and polished to a flat mirror-like surface. The distributions of Vickers microhardness along the disk diameter were measured with incremental steps of $0.5 \mathrm{~mm}$ using a Zwick microhardness tester at a constant load of 500 gf with dwell time of $15 \mathrm{~s}$. Each reported data point represents the mean of four separate indentations all made at an equal distance to the centre of the disk. In order to evaluate microstructure evolution during HPT processing, the variation of microhardness with the imposed equivalent strain on the disk was further investigated according to the following relationships $[24,25]$ :

$$
\begin{aligned}
& \varepsilon_{e q}=\frac{2}{\sqrt{3}} \ln \left[\left(1+\frac{\gamma^{2}}{4}\right)^{1 / 2}+\frac{\gamma}{2}\right] \\
& \gamma=\frac{2 \pi r N}{h}
\end{aligned}
$$

where $\gamma$ represents the shear strain, $r$ is the radial distance from disk centre, $h$ is the thickness of the disk and $N$ is the total number of torsional revolutions.

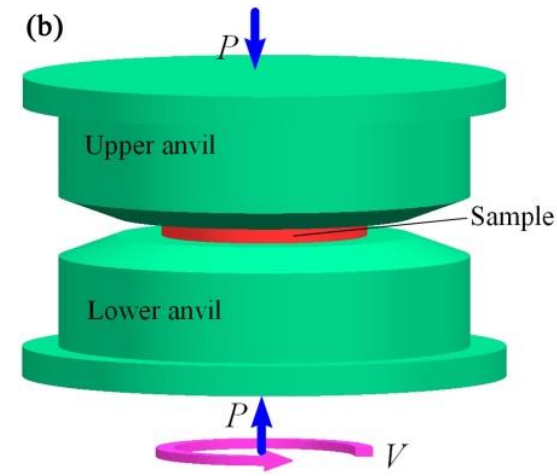

Fig. 1 (a) Dimensions of disk and anvils for HPT processing; (b) Schematic illustration of the HPT facility.

\section{Results and analysis}

\subsection{Microstructure evolution after HPT processing}

Optical microscopy (not presented) showed that the mean grain size after ageing treatment is $92 \mu \mathrm{m}$. Fig. 2 shows that at this stage a lamellar-shaped phase and dense fine lens-shaped precipitates are present in the grains (see Fig. 2(a) and (b)). According to the corresponding selected area electron diffraction (SAED) patterns shown in Fig. 2(c), the lamellae are identified as the $14 \mathrm{H}$ LPSO structure, and extra diffraction spots appearing at the positions of $1 / 4(01 \overline{1} 0)_{\alpha-M g}, \quad 2 / 4(01 \overline{1} 0)_{\alpha-M g}$ and 3/4(01 $\left.\overline{1} 0\right)_{\alpha-M g}$ demonstrate the formation of semi-coherent metastable $\beta^{\prime}$ precipitates $\left(\mathrm{Mg}_{7} \mathrm{RE}\right.$, base centered orthorhombic (bco) structure, $a=0.64 \mathrm{~nm}, b=2.28 \mathrm{~nm}$, $c=0.52 \mathrm{~nm})$ with the orientation relationship $\quad(001)_{\beta^{\prime}}$ $/ /(0001)_{\text {matrix }},[100]_{\beta^{\prime}} / /[2 \overline{1} \overline{1} 0]_{\text {matrix }}[5,26,27]$. These $\beta^{\prime}$ phase precipitates have an average size of $13 \pm 3 \mathrm{~nm}$. They precipitated on the $\{11 \overline{2} 0\}_{\alpha-M g}$ planes.

Fig. 3 exhibits the microstructure of the sample processed by 1 turn $\left(\varepsilon_{\mathrm{eq}}=3.4\right)$. Fig. 3(a) shows that the deformation starts with the generation of deformation twinning and dislocation multiplication. The mirror image symmetry of diffraction spots with respect to $\{10 \overline{1} 1\}$ plane seen in SAED patterns in Fig.3 (b) indicates that the twins are $\{10 \overline{1} 1\}<11 \overline{2} 0\rangle$ compression twins [28]. 

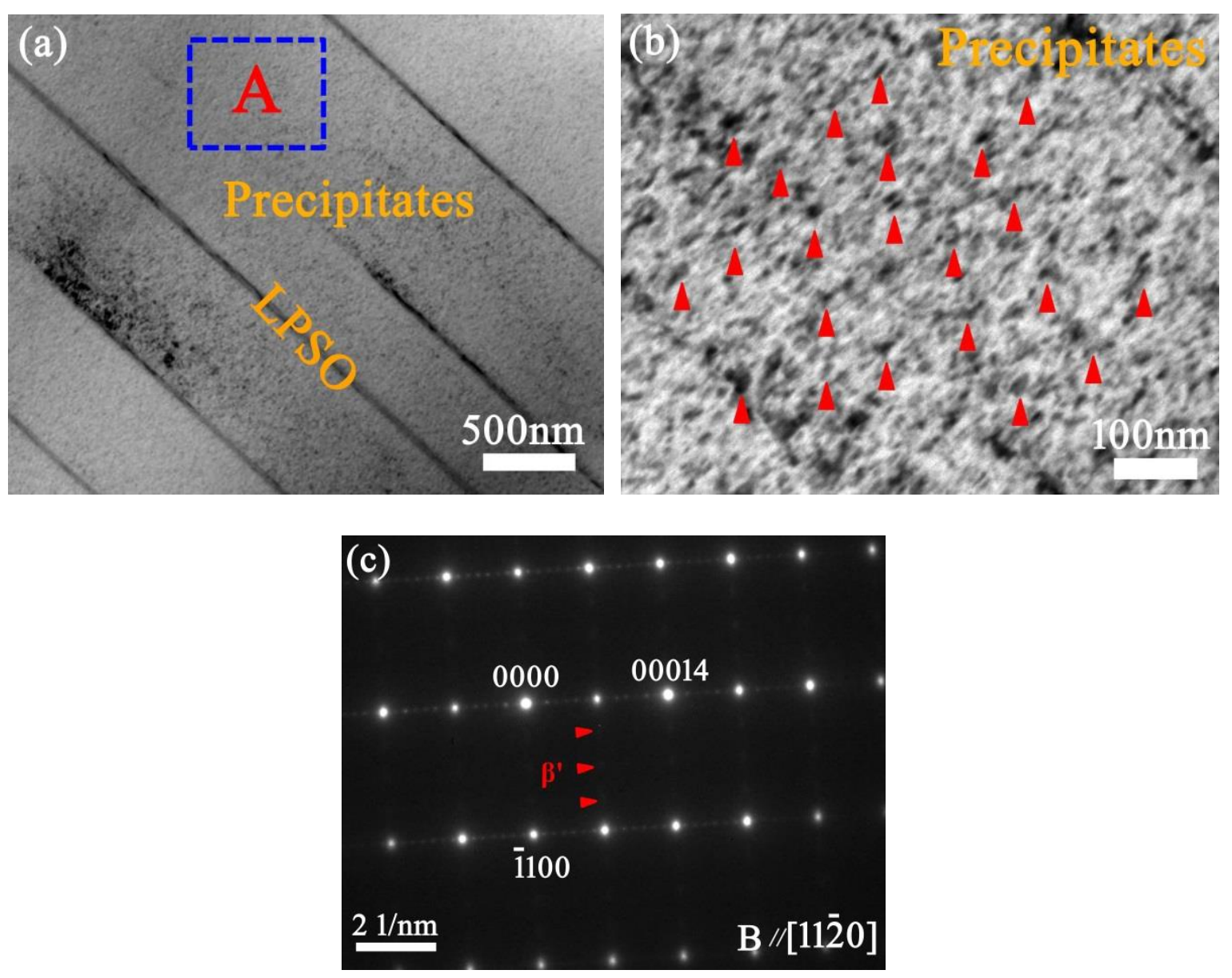

Fig.2 Microstructures of the peak-aged Mg-Gd-Y-Zn-Zr alloy sample before HPT processing: (a) TEM bright field image; (b) TEM bright field image of region A marked in (a) with electron beam // [11 $\overline{2} 0]$, and (c) The corresponding selected area electron diffraction (SAED) patterns.

Due to the limited independent slip systems in the hexagonal closed-packed (HCP) crystal structure of the Mg-rich phase, deformation twinning overwhelmingly occurs at the early stage of deformation at room temperature, serving as an additional deformation mechanism to dislocation slip [29]. The simultaneous addition of RE elements and $\mathrm{Zn}$ further facilitates twinning in deformed coarsegrained $\mathrm{Mg}$ alloys, as it reduces the stacking fault energy (SFE) [30, 31]. Fig. 3(c)-(e) shows that after the processing for 1 turn a dense distribution of precipitates remains present in large grains, with corresponding SAED patterns exhibiting isolated reflections. Such fine particles act as barriers for dislocation movement leading to an increased dislocation density [19]. Compared with the initial peak-aged sample (Fig. 2(b)), the volume fraction of $\beta^{\prime}$ phase precipitates is slightly reduced, indicating that some of the $\beta^{\prime}$ phase precipitates have dissolved into the $\alpha-\mathrm{Mg}$ matrix.

Fig.4 shows the microstructure of the sample processed by HPT for 2 turns $\left(\varepsilon_{\mathrm{eq}}=4.2\right)$. Fig. 4(a) and (b) reveal that at this stage no deformation twins are present and instead a high density of dislocation pileups and cells have been produced. The corresponding SAED patterns in Fig. 4(c) exhibit partial diffraction rings with superimposed scattered spots and arcs, indicating that subgrains with low angle boundaries have formed. 

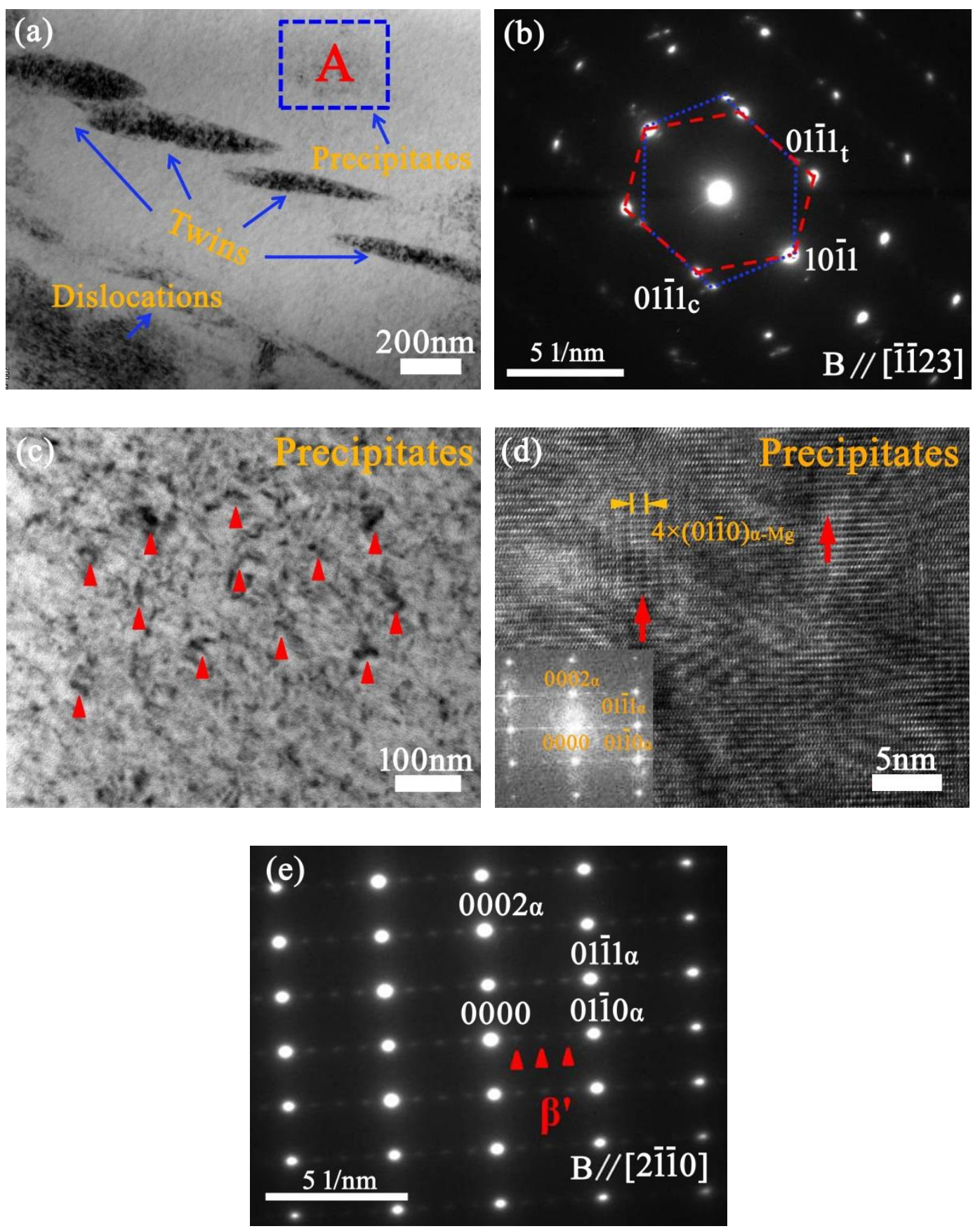

Fig.3 Microstructures of the HPT1 ( $\left.\varepsilon_{\mathrm{eq}}=3.4\right)$ sample: (a) TEM bright field image; (b) The corresponding SAED patterns of twin system of $\{10 \overline{1} 1\}<10 \overline{1} 2>$; (c) TEM bright field image of region A marked in (a) with electron beam $/ /[2 \overline{1} \overline{1} 0]$; (d) HRTEM image of precipitates and Fast Fourier Transform (FFT) image inserted, and (e) The corresponding SAED patterns of (c).

Whilst it is difficult to identify individual $\beta^{\prime}$ precipitates due to the numerous dislocations and subgrains, weak diffraction spots marked by yellow squares in Fig. 4(c) do indicate a small amount of precipitates remains. The corresponding dark field TEM image of the precipitates (Fig. 4(d)) indicates that at this level of strain, the amount of $\beta^{\prime}$ phase precipitates has decreased remarkably (marked as red 
triangles). Unlike the initial peak aged state, the inhomogeneous contrasts within the precipitates suggest that the $\beta^{\prime}$ precipitates are heavily deformed and sheared by dislocations. It has recently been demonstrated that rod-shaped precipitates of $10 \mathrm{~nm}$ radius in a $\mathrm{Mg}-5 \mathrm{Zn}$ (wt.\%) alloy are shearable during micropillar compression test [32], while the ordered prismatic plate-shaped $\beta^{\prime}$ precipitates in a WE43 $\mathrm{Mg}$ based alloy can be sheared by basal slip of $\langle a\rangle$ dislocations of [33]. From the present TEM observations, it can be deduced that during HPT processing the nanosized $\beta^{\prime}$ precipitates are sheared by many dislocations and eventually decompose.
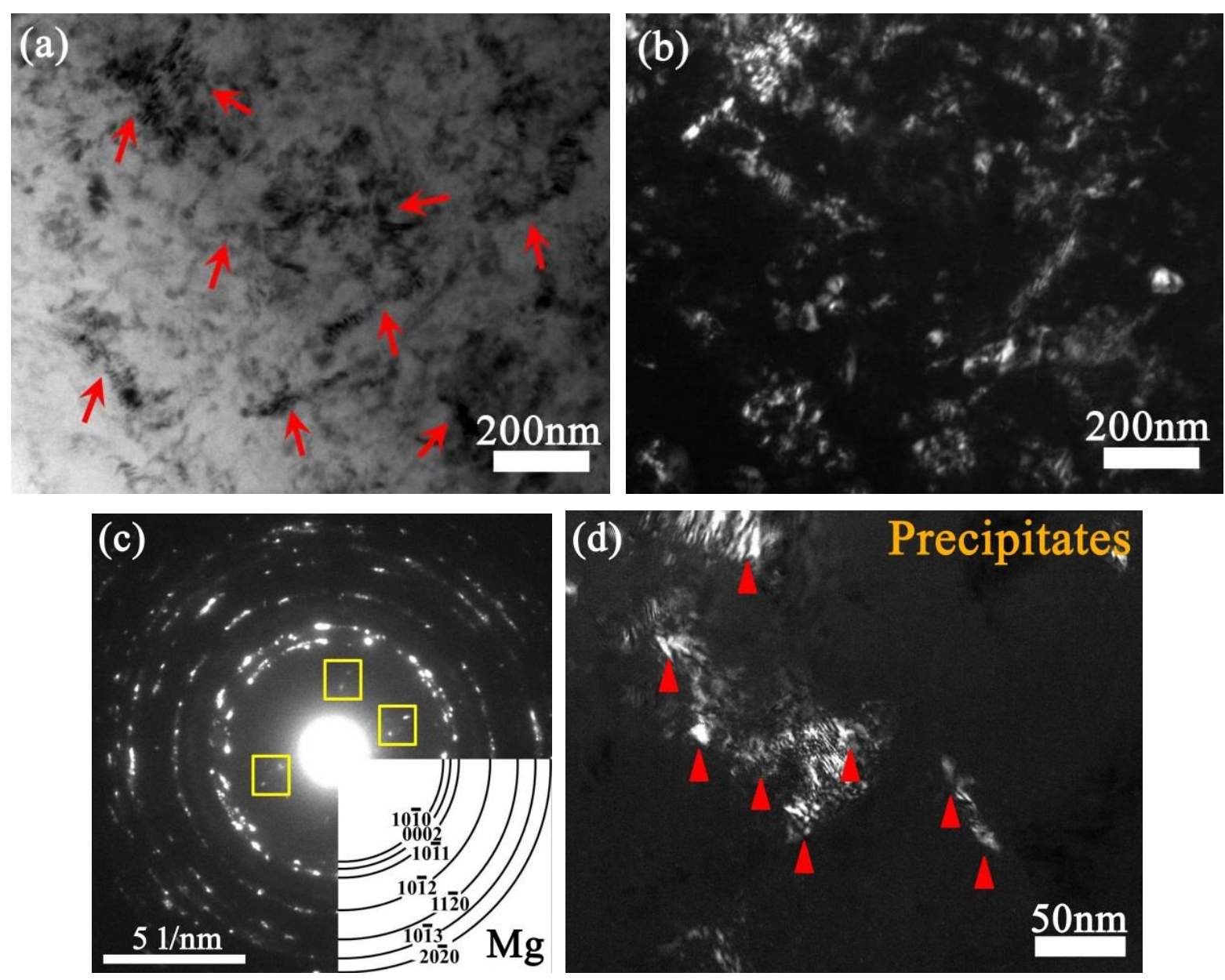

Fig.4 Microstructures of HPT2 ( $\varepsilon_{\mathrm{eq}}=4.2$ ): (a) TEM bright field image (the dislocation pile-ups are marked as red arrows); (b) TEM dark field image of (a); (c) The corresponding SAED patterns of (a); (d) TEM dark field image of precipitates using precipitate beam (the residual precipitates are marked as red triangles).

Fig. 5 shows the microstructure of the sample processed by 10 turns $\left(\varepsilon_{\mathrm{eq}}=6.0\right)$. At this stage, the grains have been further refined to an average size of $\sim 62 \mathrm{~nm}$ (see Fig.5 (a) and (b)). As shown in the SAED patterns of Fig. 5(c), the rings of spots due to the $\alpha-\mathrm{Mg}$ matrix become more continuous and a diffraction spot (indicated by yellow square) caused by precipitate remnants is weaker than those of the sample deformed by 2 turns of HPT (see Fig. 4(c)). These observations are ascribed to the grain refinement and a reduction in the amount of $\beta^{\prime}$ phase. Although the undissolved $\beta^{\prime}$ precipitates can be examined in SAED patterns, the high level of internal elastic stresses and distortions prevent their detection in TEM imaging. 

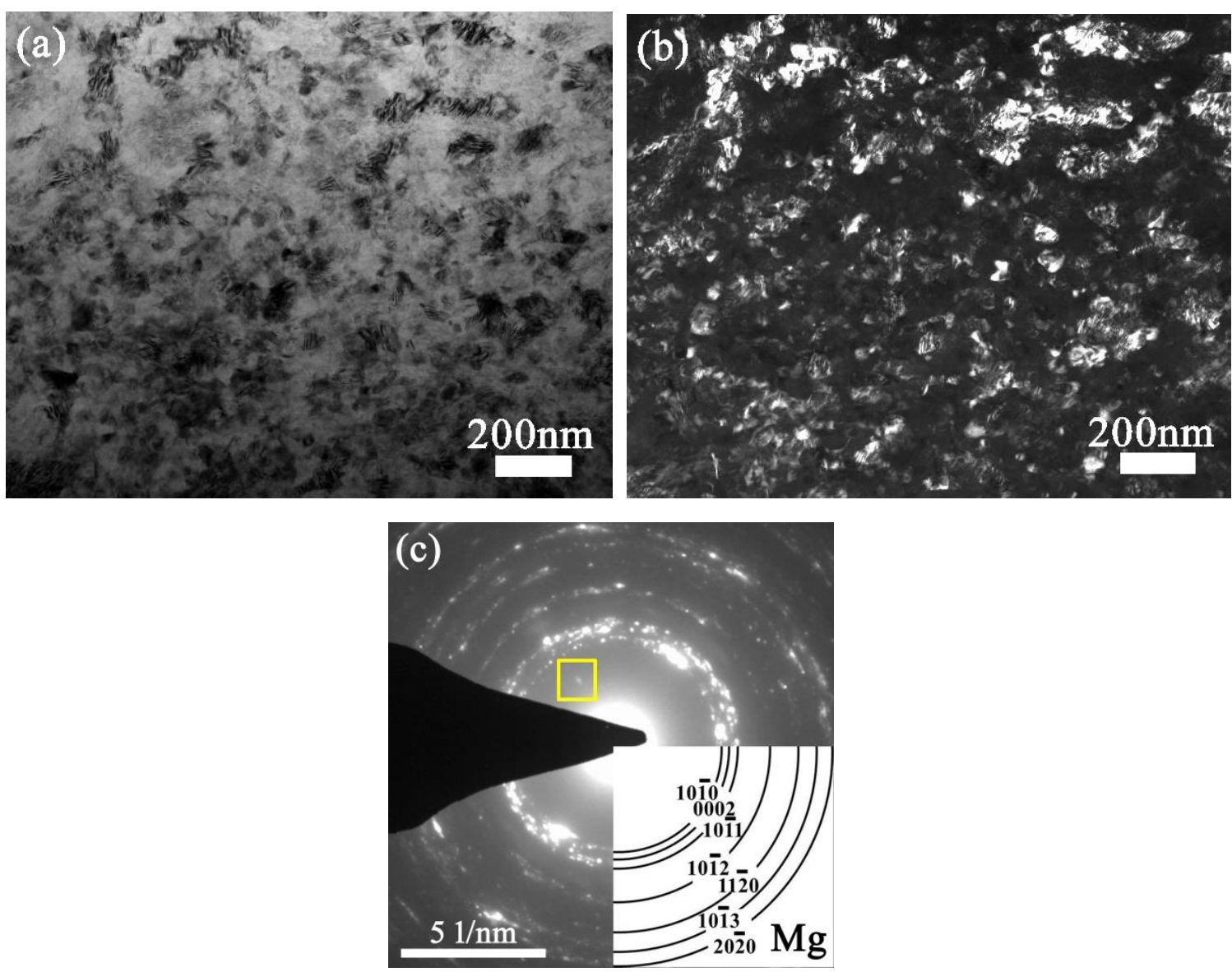

Fig.5 Microstructures of HPT10 ( $\left.\varepsilon_{\mathrm{eq}}=6.0\right)$ : (a) TEM bright field image; (b) TEM dark field image of (a); (c) The corresponding SAED patterns of (a).

The microstructure of the sample deformed by HPT for 16 turns is shown in Fig. 6. The TEM observations and the histogram of grain size distribution (Fig. 6(a), (b) and (d)) show that the refined grains have a relatively narrow size distribution and the averaged size is around $33 \mathrm{~nm}$. The SAED patterns in Fig. 6(c) contain a series of well-defined concentric rings of single-phase $\mathrm{Mg}$, which indicates the formation of nanocrystalline grains with high angle grain boundaries. Neither diffraction spots nor diffraction rings corresponding to the diffraction angles for $\beta^{\prime}$ phase can be detected, indicating that all precipitates dissolve after 16-turns HPT. Apparently the initial fine precipitates completely dissolve and a nanostructured supersaturated solid solution is achieved when a sufficiently large strain is applied by HPT processing. 

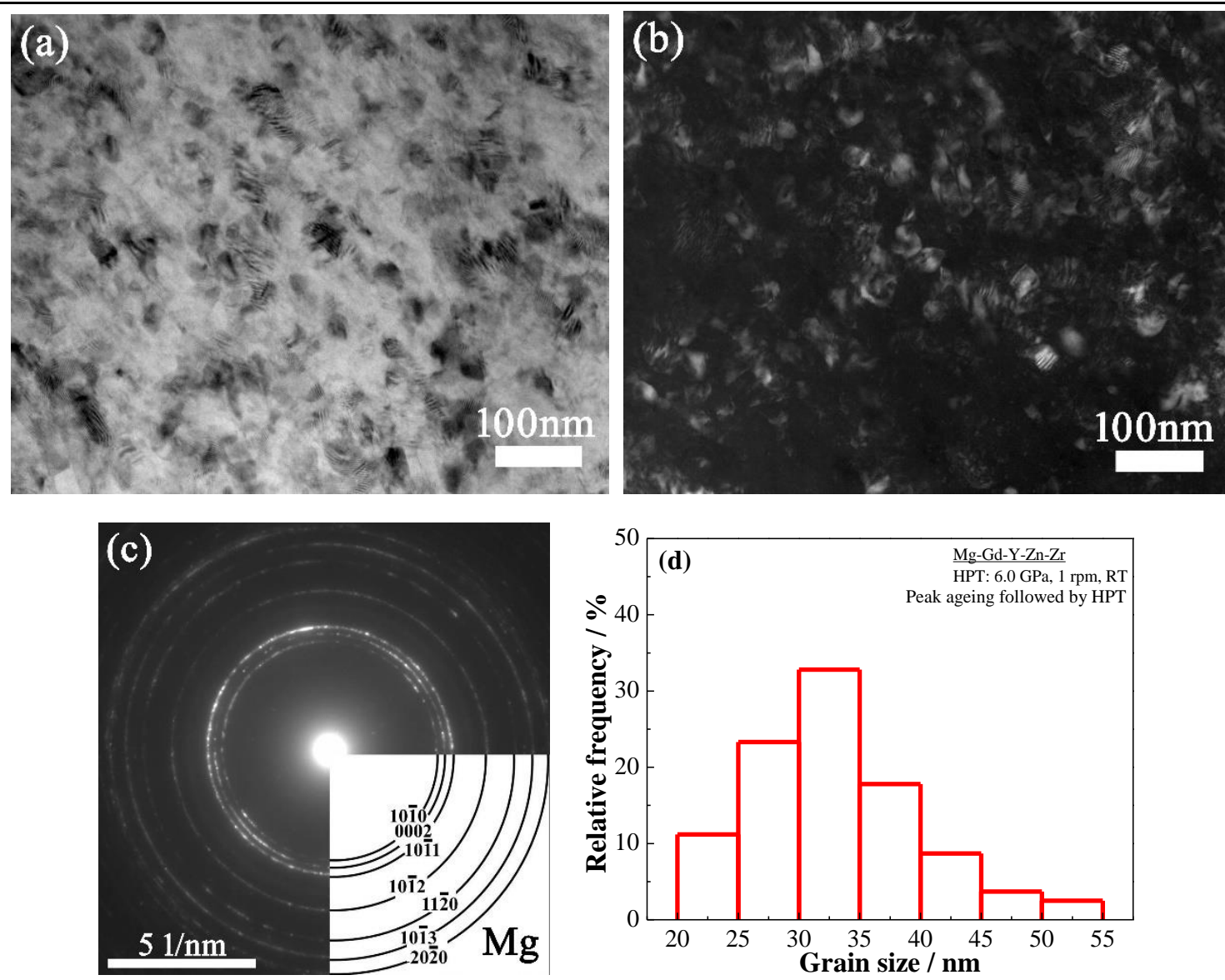

Fig.6 Microstructures of HPT16 ( $\varepsilon_{\mathrm{eq}}=6.6$ ): (a) TEM bright field image; (b) TEM dark field image of (a); (c) The corresponding SAED patterns of (a); (d) Histogram for the distribution of grain sizes.

\subsection{XRD analysis}

Fig.7 shows XRD patterns of the HPT-processed Mg-Gd-Y-Zn-Zr samples as well as the conventionally processed and subsequently peak-aged sample (i.e. prior to HPT). The XRD pattern of the undeformed sample demonstrates the presence of metastable $\beta^{\prime}$ precipitates prior to deformation (see Fig. 7(a)). After $1 / 8$ turn of HPT, the intensities of peaks due to $\beta^{\prime}$ phase are decreased, indicating the amount of $\beta^{\prime}$ precipitates is reduced by partial dissolution, while there is no evidence of precipitates after 1 turn (their amount is below the threshold level for the detection by XRD measurement). In the enlarged sections of the spectra between $30^{\circ}$ and $40^{\circ}$ shown in Fig. 7(b), dash lines are used to compare the positions of (100), (002) and (101) peaks arising from Mg matrix after HPT with their positions before HPT. It can be seen that all peaks due to $\alpha-\mathrm{Mg}$ are shifted towards a lower angle by HPT deformation, further suggesting that precipitates gradually dissolve into the $\alpha-\mathrm{Mg}$ matrix. 

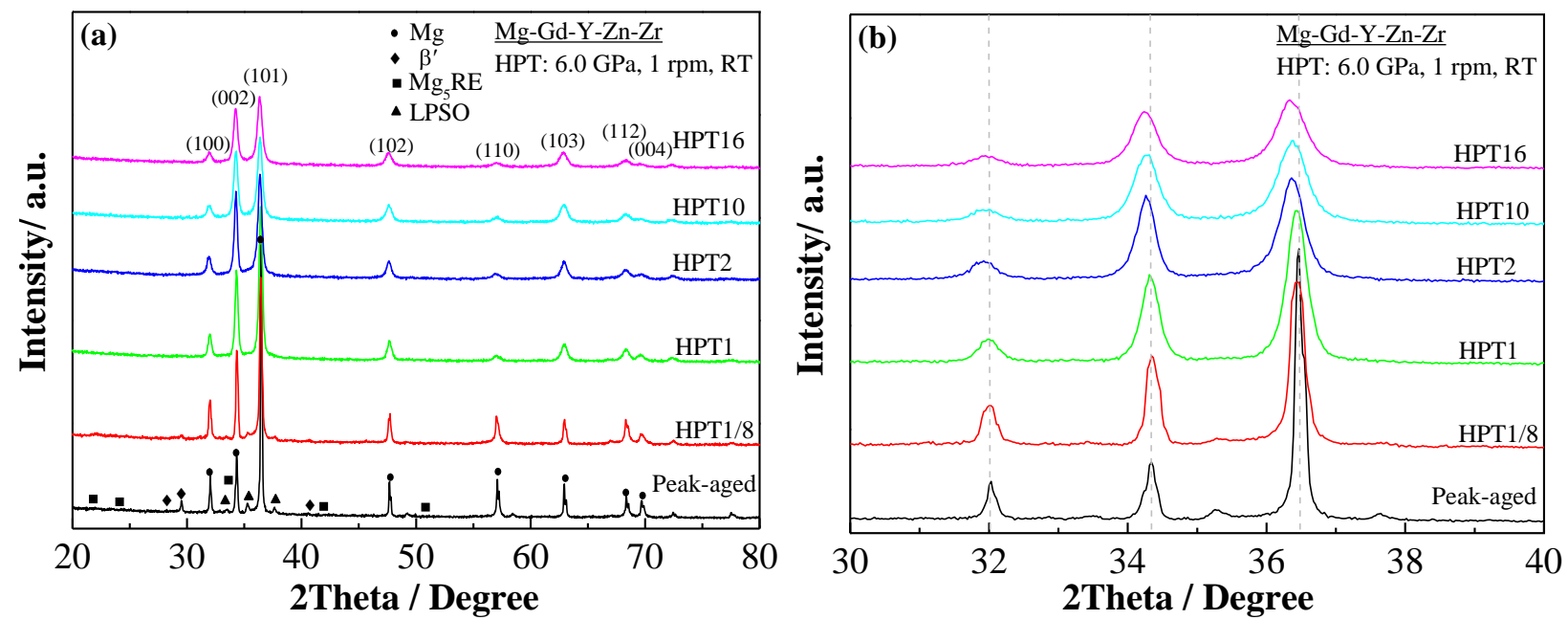

Fig. 7 (a) XRD patterns of the peak-aged and HPT-processed Mg-Gd-Y-Zn-Zr alloy with various revolutions; (b) Section of the XRD patterns in the range from $30^{\circ}$ to $40^{\circ}$.

A significant decrease in intensity and simultaneous increase in width of the $\alpha-\mathrm{Mg}$ peaks are also observed. This is attributed to the reduced crystallite size and the high internal microstrains induced by HPT deformation. The changes in crystallite size, dislocation density and lattice axial ratio $c / a$ with different revolutions during HPT are given in Fig. 8. The crystallite sizes estimated from the measured peak broadening of the XRD patterns are smaller than those obtained by TEM observations [20], but the trend is consistent. Compared with the peakaged sample, the lattice axial ratio $c / a$ is decreased with HPT turns, which is similar to the values of Mg-Gd-YZn-Zr solid solution deformed by HPT under the same conditions [14]. It reveals that a supersaturated solid solution is achieved and strong lattice distortion is produced by the dissolution of the RE alloying elements into $\alpha-\mathrm{Mg}$ matrix owing to their larger atomic radius.

Fig. 8 also shows that with increasing HPT turns the dislocation density increases. With increasing strain, a considerable fraction of precipitates are sheared and subsequently decompose. After the metastable $\beta^{\prime}$ phase precipitates are dissolved, the increased contents of solutes in the $\mathrm{Mg}$ matrix will retard the dislocation annihilation through the enhanced solute-dislocation / dislocation-dislocation interactions. As a consequence, the dislocation density is increased to $\sim 4.8 \times 10^{14} \mathrm{~m}^{-2}$ in the supersaturated solid solution after HPT for 16 turns, which is close to that of solution-treated $\mathrm{Mg}-\mathrm{Gd}-\mathrm{Y}-\mathrm{Zn}-\mathrm{Zr}$ processed by HPT of 16 turns $\left(\sim 4.7 \times 10^{14} \mathrm{~m}^{-2}\right)$ [14]. The present HPT-processed peak-aged Mg-Gd-Y-Zn-Zr material has a higher dislocation density than the HPTprocessed as-cast $\mathrm{Mg}-\mathrm{Gd}-\mathrm{Y}-\mathrm{Zn}-\mathrm{Zr}$ material $(\sim 3.2 \times$ $\left.10^{14} \mathrm{~m}^{-2}\right)$, which was studied previously [13]. This indicates that for dislocation accumulation during severe plastic deformation processing, a distribution of fine precipitates is more effective than the coarse second phases particles found in as-cast (and as-cast and homogenized) materials. 


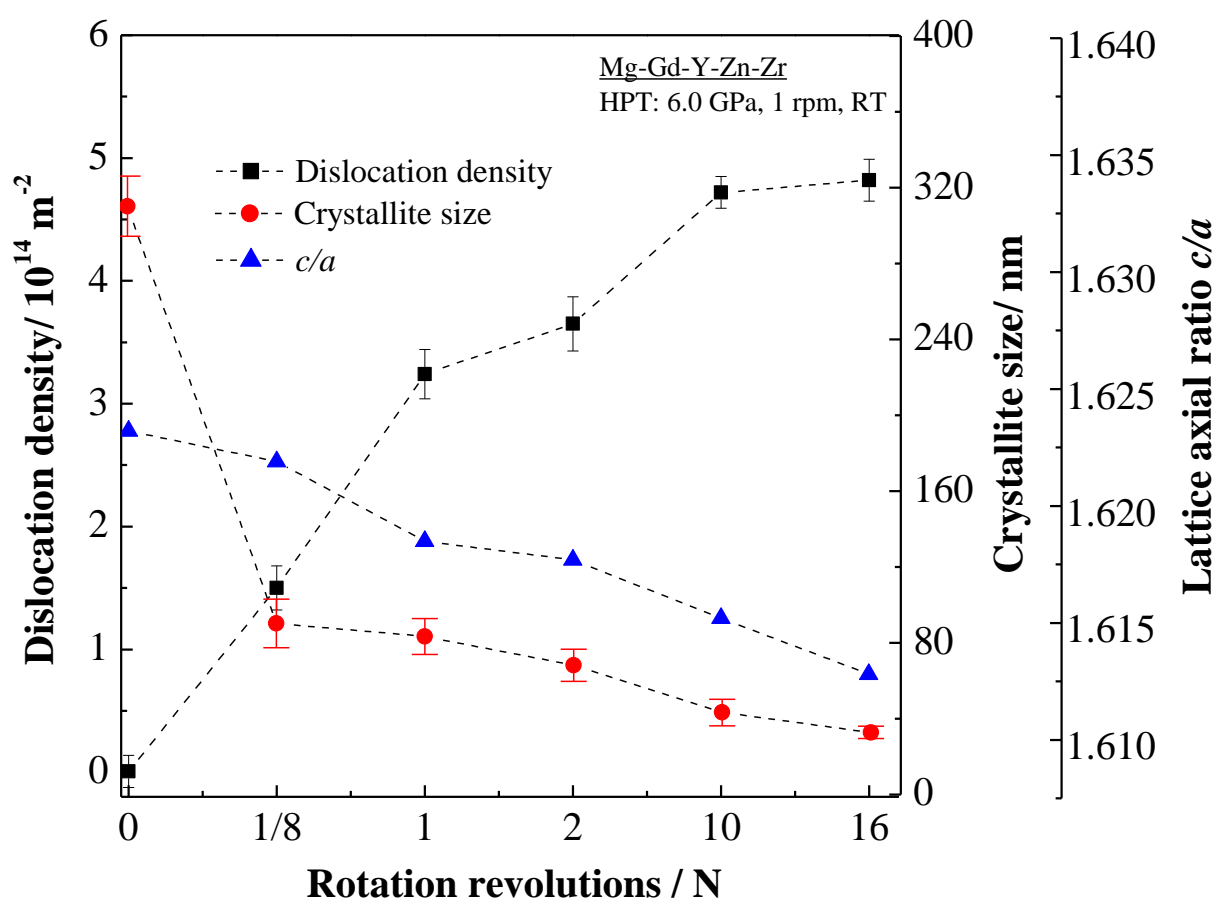

Fig. 8 Dependence of crystallite size, dislocation density and lattice axial ratio of the peak-aged and subsequently HPT-processed Mg-Gd-Y-Zn-Zr alloy on the number of the HPT revolutions.

\subsection{Microhardness evolution and strain hardening behavior during HPT processing}

The hardness distribution along the diameter of each HPT-processed disk is shown in Fig. 9(a). After HPT processing, the hardness of all the HPT-processed samples are drastically increased in comparison with the peak-aged counterpart. The variation of hardness is not only associated with the number of revolutions but also with the distance from the centre of disks. For both $1 / 8$ turn and 1 turn, the hardness is relatively low at the centre and high at the outer region of the disk owing to the limited plastic deformation in the central area. However, the hardness is unexpectedly decreased after HPT for 16 turns, especially for the peripheral area, and the hardness maximum appears at shorter distances from the centre. These observations can be explained by the decomposition of metastable $\beta^{\prime}$ phase precipitates during HPT, which leads to a reduction in the precipitation hardening effect (see Discussion, section 4.1). In Fig. 9(b), the hardness evolution is plotted as a function of the equivalent strain. As the equivalent strain increases, the hardness initially increases, but after the equivalent strain surpasses $\sim 3.7$ the hardness starts to decrease, and finally (beyond an equivalent strain of $\sim 7$ ) it remains nearly unchanged.

\section{Discussion}

\subsection{Microstructure evolution: precipitate dissolution} and exceptional grain refinement

The present work shows that the RE containing $\beta^{\prime}$ phase precipitates dissolve during SPD. Strain-induced decomposition of fine second phases during SPD was also observed in other alloys. Cementite in pearlitic steel was reported to dissolve into the matrix during HPT processing at room temperature [34]. The $\mathrm{Mg}_{2} \mathrm{Si}$ precipitates in a $6082 \mathrm{Al}$ alloy had a tendency to fragment and dissolve owing to severe strains induced by equal channel angular pressing (ECAP) at room temperature [35], whilst ECAP processing of an aged Al-1.7 at.\% $\mathrm{Cu}$ alloy for one pass at room temperature caused the decomposition of the $\theta^{\prime}$ phases [36]. 

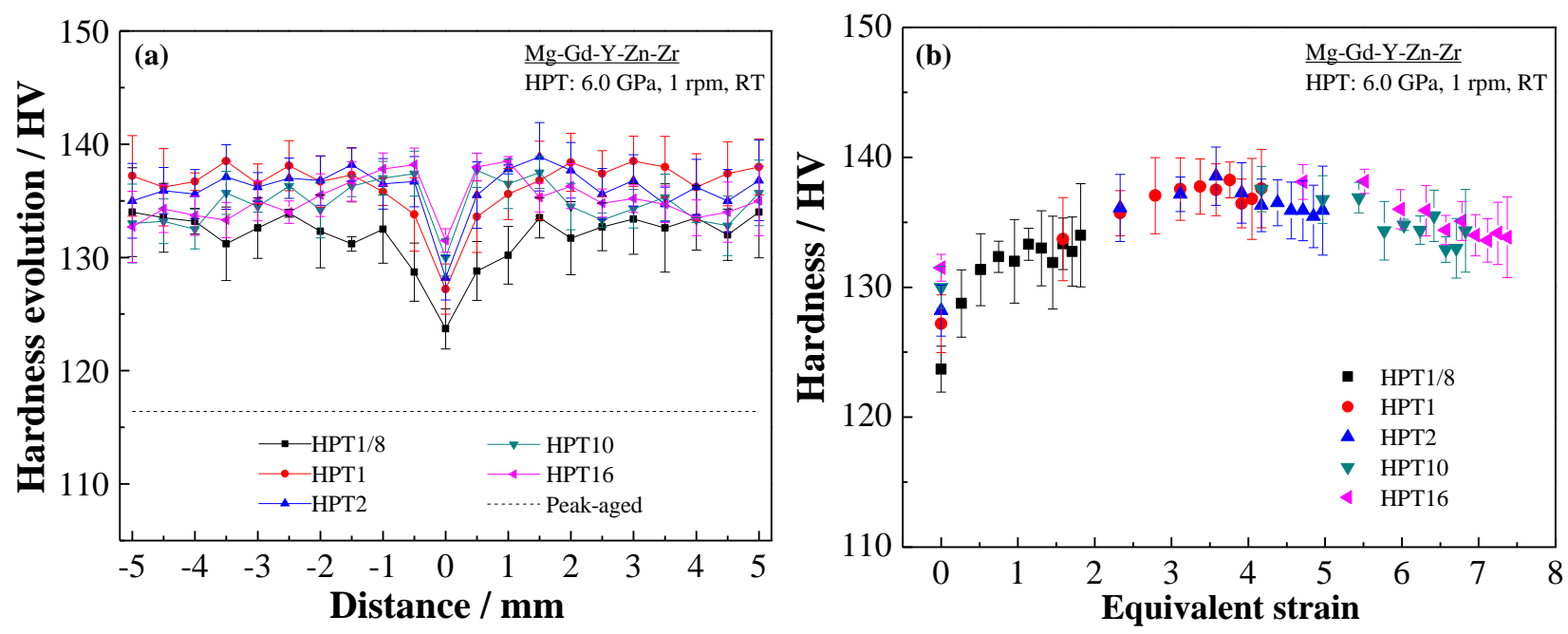

Fig. 9 (a) Variation of the Vickers microhardness across the diameter of the different HPT-processed disks, where the microhardness of the initial peak-aged material is presented by the dashed line; (b) The microhardness as a function of the equivalent strain of HPT disks.

In general, the decomposition of precipitates is ascribed to the interactions between the precipitates and defects at the interface or within the precipitates during deformation [33, 34, 37-42]. With increasing strains the free energy of the refined precipitates is increased due to the increase of precipitate-matrix surface area (i.e. the Gibbs-Thomson effect), i.e. the fragmented and deformed nanoscale particles can become unstable due to high surface energy. The high dislocation density created by HPT processing also plays a crucial role in particle dissolution, by enhancing the atomic diffusion through the wellknown pipe diffusion mechanism. In addition, the high defect density in the $\alpha-M g$ matrix will provide energetically favourable sites for RE atoms to form defect-solute clusters $[14,20]$, which can create a further driving force for $\beta^{\prime}$ precipitates to dissolve. As a result of these processes, a nanostructured supersaturated solid solution may be achieved after HPT processing. It is should be noted that the evolution of different second phases during HPT deformation is related to their stability, i.e. interatomic binding energy. The $\beta^{\prime}$ precipitates differ from the equilibrium $\mathrm{Mg}_{3} \mathrm{RE}$ phases in their thermal stability and are easier to dissolve during HPT resulting in diffusion of solute atoms into the $\alpha-\mathrm{Mg}$ matrix.

The TEM observations have shown that after HPT for 16 turns the average grain size is $\sim 33 \mathrm{~nm}$ (Fig. 6 ), which is smaller than the grain size of as-cast and solution-treated Mg-Gd-Y-Zn-Zr processed by HPT $[13,14]$. The grain refinement mechanism during HPT is controlled by the generation of dislocations and their dynamic reorganization into low angle grain boundaries and finally high angle grain boundaries at large strains [11, 12, 43]. The grain refinement is influenced by the amount and distribution of precipitates or dispersoid particles [19, 38]. During the HPT processing, dislocations tend to tangle around the fine $\beta^{\prime}$ precipitates and thus an increased density of dislocations is created, which facilitates the grain refinement of the alloy [19]. This mechanism thus explains why the grain refinement during HPT is stronger for a material that is age hardened as compared to a solution treated or as-cast material. 
Comparison with data on a wide range of $\mathrm{Mg}$ alloys processed by HPT shows that the present processing of the T6-treated Mg-Gd-Y-Zn-Zr alloy results in a grain size that is the smallest ever reported for a $\mathrm{Mg}$ alloy [29, 44-52]. It is also substantially smaller than grain sizes reported for SPD processed Al-based alloys [19].

\subsection{Strain hardening and softening}

In order to evaluate the hardening and softening behaviour of the present peak-aged Mg-Gd-Y-Zn-Zr alloy during HPT processing, a double logarithmic plot of microhardness values against equivalent strains is given in Fig. 10(a). Unlike the HPT processing of ascast and solution-treated Mg-Gd-Y-Zn-Zr alloy [13, 14], in which the hardness monotonously increased until saturation was reached, the HPT processing of the present peak-aged samples causes three distinctive stages (see Fig.9(b)). During the first stage, the hardness increases up to a maximum of $139 \mathrm{HV}$ at $\varepsilon_{\mathrm{eq}} \sim 3.7 \quad\left(\ln \varepsilon_{\mathrm{eq}}=1.3\right)$. This strain hardening is predominantly due to the increase in dislocation density and reduction in grain size (see Fig. 8). The solid straight line shown in Fig. 10(a) provides the relationship for the hardness and equivalent strains $H V \approx 133 \mathrm{HV} \varepsilon_{e q}^{0.03}\left(\varepsilon_{\mathrm{eq}} \leq 3.7\right)$, where the unit of hardness is $\mathrm{HV}$, and the exponent $[44,45]$ determined by the slope is $\sim 0.03$. By contrast, for the HPT processing of as-cast and solution-treated $\mathrm{Mg}-\mathrm{Gd}-\mathrm{Y}$ $\mathrm{Zn}-\mathrm{Zr}$ alloy, the exponents are larger $\sim 0.05$ and $\sim 0.09$, respectively [14]. This difference is thought to be mainly due to the progressive dissolution of $\beta^{\prime}$ precipitates which progressively reduces the critical resolved shear stress of the grains, and thus has a negative effect on the hardening rate. This shows that the hardening capability is strongly dependent on the heat treatment prior to HPT deformation, i.e. it is strongly dependent on the initial microstructure. During the second stage, further increase of strain causes a gradual slight decrease in the hardness (see Fig. 9(b)). The corresponding linear relationship in the double logarithmic plot in Fig. 10 (a) is $H V \approx$ $144 \mathrm{HV} \varepsilon_{e q}^{-0.04}\left(\varepsilon_{\mathrm{eq}}>3.7\right)$ and the exponent is -0.04 (i.e. the exponent is now negative). This softening is thought to be due to continued dissolution of $\beta^{\prime}$ precipitates which now is more important than the hardening due to the increasing dislocation density, because the dislocation density is starting to approach saturation. At the third stage, after $\varepsilon_{\mathrm{eq}} \sim 6.7$, the hardness enters into a steady level of $\sim 134 \mathrm{HV}$, remaining unchanged with further straining (see Fig. 9(b)). The TEM data, in conjunction with the dislocation density and grain size data in Fig. 8, indicate that this is due to $\beta^{\prime}$ dissolution having completed and grain size and dislocation density having reached a near stable state, e.g. all main strengthening mechanisms reach a near stable state.

The hardness distributions of samples HPT processed for 16 turns starting from three different initial states, i.e. as-cast, solution-treated and peakaged alloys, are shown in Fig. 10(b). The sample that was peak-aged (i.e. containing a high density of $\beta^{\prime}$ precipitates) and subsequently HPT processed exhibits the highest hardness. The saturated values of HPTprocessed cast and HPT-processed solution-treated samples are lower than that of the HPT-processed peak-aged one by $\sim 19 \mathrm{HV}$ and $\sim 8 \mathrm{HV}$, respectively. A quantitative assessment of the differences in hardness between these samples can be obtained as follows. The grain boundary hardening is described by the HallPetch relationship:

$$
\triangle H V_{G B}=C k_{H P} d^{-1 / 2}
$$

where $k_{H P}$ is the Hall-Petch coefficient taken as $\sim 40.7 \mathrm{MPa} / \mu \mathrm{m}^{-1 / 2}$ for $\mathrm{Mg}$ [43], and $d$ is the mean grain size. The dislocation hardening contribution can be estimated from existing models [43] as follows:

$$
\Delta H V_{D}=C M \alpha_{1} G b \sqrt{\rho}
$$

where $\rho$ is the dislocation density, $M$ is the Taylor factor, $\alpha_{1}$ is a constant of $0.3, b$ is Burgers vector 
$(0.3197 \mathrm{~nm}$ for $\mathrm{Mg}), G$ is the shear modulus $(17.7 \mathrm{GPa}$ for $\mathrm{Mg}$ ). The contributions of grain refinement and dislocations to saturated hardness for HPT-processed Mg-Gd-Y-Zn-Zr alloy are summarized in Fig. 10(c). From these results it is clear that the two dominant hardening mechanisms, to grain boundary hardening and dislocation hardening, can account for the observed differences in saturated hardness amongst these three states.

To further improve the mechanical properties of the nanostructured $\mathrm{Mg}$ alloy, a study of post-HPT ageing treatment is needed.
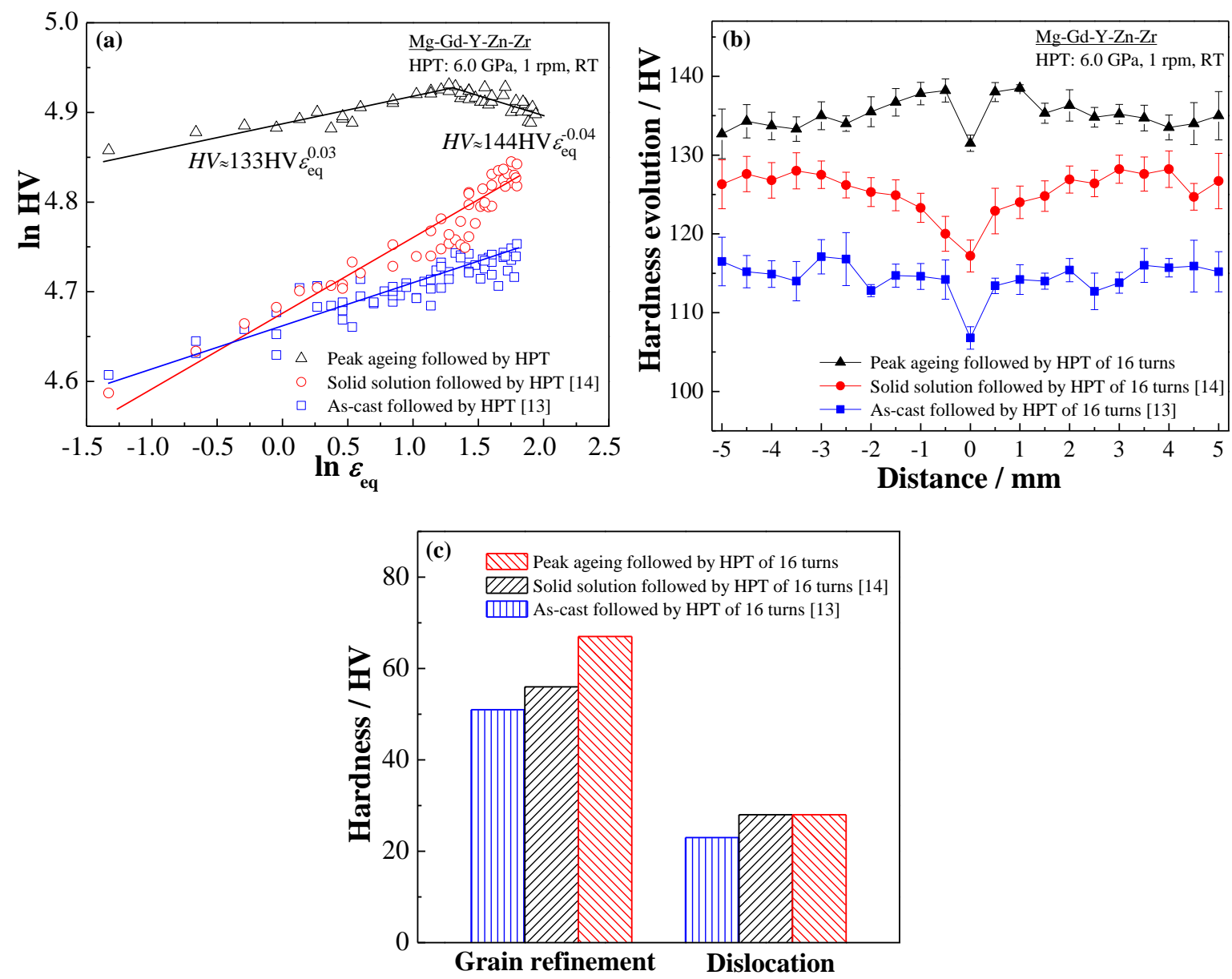

Fig. 10 (a) A double natural logarithmic plot of microhardness values versus $\varepsilon_{\text {eq }}$ for different initial states followed by HPT;

(b) Comparison of microhardness evolution after HPT of 16 turns starting from three different initial states; (c) Contributions of grain refinement and dislocations to saturated hardness for HPT-processed Mg-Gd-Y-Zn-Zr alloy.

\section{Conclusions}

In this study, the peak-aged Mg-Gd-Y-Zn-Zr alloy containing finely dispersed $\beta^{\prime}$ phase precipitates was subjected to HPT processing at room temperature. The influence of nanosized precipitates on the microstructure refinement and mechanical behaviour were investigated at different strain levels induced by HPT. The conclusions are summarized as follows:

(1) With increasing the number of revolutions, the moving dislocations cut the pre-existing semi-coherent nanosized $\beta^{\prime}$ phase precipitates, and the precipitates are gradually dissolved into the $\alpha-\mathrm{Mg}$ matrix. After 16 turns of HPT processing, the $\beta^{\prime}$ phase precipitates are 
almost completely dissolved into the $\alpha-\mathrm{Mg}$ matrix.

(2) The present processing results in exceptional grain refinement producing an average grain size of $\sim 33 \mathrm{~nm}$, which is the smallest ever reported for a bulk processed Mg- or Al-based alloy. The grain size achieved is smaller than those of as-cast and solution-treated samples of the same alloy deformed using the same HPT conditions. The semi-coherent nanosized precipitates are beneficial to the grain refinement during HPT as they act as barriers to inhibit dislocation movement and the increased solute content in the matrix due to the precipitates dissolution retards the dislocation annihilation and increases the dislocation density.

(3) With the imposed strains increasing, the hardness initially increases, but after 2 rotations the hardness decreases slightly, even though the grains size continues to decrease and the dislocation density continues to increase. This unusual strain softening is due to decomposition of the fine precipitates.

\section{References}

[1] F.S. Pan, M.B. Yang, X.H Chen, A Review on casting magnesium alloys: modification of commercial alloys and development of new alloys, J. Mater. Sci. Technol. 32 (2016) 1211-1221.

[2] M.K. Kulekci, Magnesium and its alloys applications in automotive industry, Int. J. Adv. Manuf. Technol. 39 (2008) 851-865.

[3] J. Wang, J. Meng, D.P. Zhang, D.X.Tang, Effect of Y for enhanced age hardening response and mechanical properties of Mg-Gd-Y-Zr alloys, Mater. Sci. Eng. A 456 (2007) 78-84.

[4] L. Gao, R.S. Chen, E.H. Han, Effects of rare-earth elements $\mathrm{Gd}$ and $\mathrm{Y}$ on the solid solution strengthening of Mg alloys, J. Alloys Compd. 481 (2009) 379-384.

[5] C. Xu, M.Y. Zheng, K. Wu, E.D. Wang, G.H. Fan, S.W. Xu, S. Kamado, X.D. Liu, G.J. Wang, X.Y. Lv, Effect of ageing treatment on the precipitation behaviour of $\mathrm{Mg}-\mathrm{Gd}-$ Y-Zn-Zr alloy, J. Alloys Compd. 550 (2013) 50-56.

[6] Y.Q. Chi, M.Y. Zheng, C. Xu, Y.Z. Du, X.G. Qiao, K. Wu, X.D. Liu, G.J. Wang, X.Y. Lv, Effect of ageing treatment on the microstructure, texture and mechanical properties of extruded Mg-8.2Gd-3.8Y-1Zn-0.4Zr (wt\%) alloy, Mater. Sci. Eng. A 565 (2013) 112-117.

[7] C. Xu, M.Y. Zheng, S.W. Xu, K. Wu, E.D. Wang, S. Kamado, G.J. Wang, X.Y. Lv, Ultra high-strength Mg-Gd$\mathrm{Y}-\mathrm{Zn}-\mathrm{Zr}$ alloy sheets processed by large-strain hot rolling
Eventually a steady state hardness level of $\sim 134 \mathrm{HV}$ is reached.

(4) Under the same HPT processing parameters, the present peak-aged $\mathrm{Mg}-8.2 \mathrm{Gd}-3.8 \mathrm{Y}-1.0 \mathrm{Zn}-0.4 \mathrm{Zr}$ sample exhibits quite different microstructure evolution and hardening behaviour during HPT processing as compared to both the cast and the solutionized $\mathrm{Mg}-\mathrm{Gd}-\mathrm{Y}-\mathrm{Zn}-\mathrm{Zr}$ alloy, in which the hardness increases monotonically with increasing strains. Despite the loss of precipitation hardening, the hardness is still higher than those of as-cast and solution-treated alloy followed by HPT, which is ascribed to the stronger grain refinement and higher dislocation density.

\section{Acknowledgements}

This work was supported by National Key Research and Development Program of China (No. 2016YFB0301102) and National Natural Science Foundation of China (No 51571068 and 51771062).

and ageing, Mater. Sci. Eng. A 547 (2012) 93-98.

[8] C. Xu, T. Nakata, X. G. Qiao, M. Y. Zheng, K. Wu, S. Kamado, Ageing behavior of extruded Mg-8.2Gd-3.8Y$1.0 \mathrm{Zn}-0.4 \mathrm{Zr}$ (wt.\%) alloy containing LPSO phase and $\gamma^{\prime}$ precipitates, Sci. Rep. 7 (2017) 43391-43402.

[9] C. Xu, T. Nakata, X.G. Qiao, M.Y. Zheng, K. Wu, S. Kamado, Effect of LPSO and SFs on microstructure evolution and mechanical properties of $\mathrm{Mg}-\mathrm{Gd}-\mathrm{Y}-\mathrm{Zn}-\mathrm{Zr}$ alloy, Sci. Rep. 7 (2017) 40846-40855.

[10] J.Y. Han, J. Chen, L.M. Peng, S. Tan, H. Yi, Microstructure, texture and mechanical properties of friction stir processed Mg-14Gd alloys, Mater. Des. 130 (2017) 90102.

[11] K. Edalati, Z. Horita, A review on high-pressure torsion (HPT) from 1935 to 1988, Mater. Sci. Eng. A 652 (2016) 325-352.

[12] A.P. Zhilyaev, T.G. Langdon, Using high-pressure torsion for metal processing: fundamentals and application, Prog. Mater. Sci. 53 (2008) 893-979.

[13] W.T. Sun, C. Xu, X.G. Qiao, M.Y. Zheng, S. Kamado, N. Gao, M.J. Starink, Evolution of microstructure and mechanical properties of an as-cast $\mathrm{Mg}-8.2 \mathrm{Gd}-3.8 \mathrm{Y}-1.0 \mathrm{Zn}$ $0.4 \mathrm{Zr}$ alloy processed by high pressure torsion, Mater. Sci. Eng. A 700 (2017) 312-320.

[14] W.T. Sun, X.G. Qiao, M.Y. Zheng, C. Xu, N. Gao, M.J. Starink, Microstructure and mechanical properties of a nanostructured $\mathrm{Mg}-8.2 \mathrm{Gd}-3.8 \mathrm{Y}-1.0 \mathrm{Zn}-0.4 \mathrm{Zr}$ supersaturated 
solid solution prepared by high pressure torsion, Mater. Des. 135 (2017) 366-376.

[15] R. Kocich, L. Kunčická, P. Král, T. C. Lowe, Texture, deformation twinning and hardening in a newly developed $\mathrm{Mg}-\mathrm{Dy}-\mathrm{Al}-\mathrm{Zn}-\mathrm{Zr}$ alloy processed with high pressure torsion, Mater. Des. 90 (2016) 1092-1099.

[16] C. Xu, M.Y. Zheng, Y.Q. Chi, X.J. Chen, K. Wu, E.D. Wang, G.H. Fan, P. Yang, G.J. Wang, X.Y. Lv, S.W. Xu, S. Kamado, Microstructure and mechanical properties of the $\mathrm{Mg}-\mathrm{Gd}-\mathrm{Y}-\mathrm{Zn}-\mathrm{Zr}$ alloy fabricated by semi-continuous casting, Mater. Sci. Eng. A 549 (2012) 128-135.

[17] C. Xu, Z. Horita, T.G. Langdon, The evolution of homogeneity in an aluminum alloy processed using highpressure torsion, Acta Mater. 56 (2008) 5168-5176.

[18] A. Thorvaldsen, The intercept method-1. Evaluation of grain shape, Acta Mater. 45 (1997) 587-594.

[19] M.J. Starink, X.G. Qiao, J. Zhang, N. Gao, Predicting grain refinement by cold severe plastic deformation in alloys using volume averaged dislocation generation, Acta Mater. 57 (2009) 5796-5811.

[20] Y. Chen, N. Gao, G. Sha, S.P. Ringer, M.J. Starink, Microstructural evolution, strengthening and thermal stability of an ultrafine-grained $\mathrm{Al}-\mathrm{Cu}-\mathrm{Mg}$ alloy, Acta Mater. 109 (2016) 202-212.

[21] L. Lutterotti, S. Gialanella, X-ray diffraction characterization of heavily deformedmetallic specimens, Acta Mater. 46 (1998) 101-110.

[22] G.K. Williamson, R.E. Smallman, Dislocation densities in some annealed and cold-worked metals from measurements on the X-Ray debye-scherrer spectrum, Philos.Mag.1 (1956) 34-46.

[23] M.Y. Murashkin, I. Sabirov, A.E. Medvedev, N.A. Enikeev, W. Lefebvre, R.Z. Valiev, X. Sauvage, Mechanical and electrical properties of an ultrafine grained Al-8.5 wt.\% $\mathrm{RE}(\mathrm{RE}=5.4$ wt.\% Ce, $3.1 \mathrm{wt} \%$ La) alloy processed by severe plastic deformation, Mater. Des. 90 (2016) 433-442. [24] I. Saunders, J. Nutting, Deformation of metals to high strains using combination of torsion and compression, Met. Sci. 18 (1984) 571-575.

[25] X.G. Qiao, Y.W. Zhao, W.M. Gan, Y. Chen, M.Y. Zheng, K. Wu, N. Gao, M.J. Starink, Hardening mechanismof commercially pure $\mathrm{Mg}$ processed by high pressure torsion at room temperature, Mater. Sci. Eng. A 619 (2014) 95-106.

[26] M. Nishijima, K. Hiraga, M. Yamasaki, Y. Kawamura, Characterization of $\beta^{\prime}$ phase precipitates in an Mg-5 at\% Gd alloy aged in a peak hardness condition, studied by highangle annular detector dark-field scanning transmission electron microscopy, Mater. Trans. 47 (2006) 2109-2112.

[27] M.Yamasaki, M. Sasaki, M. Nishijima, K. Hiraga, Y. Kawamura, Formation of $14 \mathrm{H}$ long period stacking ordered structure and profuse stacking faults in $\mathrm{Mg}-\mathrm{Zn}-\mathrm{Gd}$ alloys during isothermal aging at high temperature, Acta Mater. 55 (2007) 6798-6805.

[28] D. A. Basha, J. M. Rosalie, H. Somekawa, T. Miyawaki, A. Singh, K. Tsuchiya, Microstructure study of a severely plastically deformed $\mathrm{Mg}-\mathrm{Zn}-\mathrm{Y}$ alloy by application of low angle annular dark field diffraction contrast imaging, Sci. Technol. Adv. Mat. 17 (2016) 115-127.

[29] S.A. Torbati-Sarraf, T.G. Langdon, Properties of a
ZK60 magnesium alloy processed by high-pressure torsion, J. Alloys Compd. 613 (2014) 357-363.

[30] B. Smola, I. Stulikova, J. Pelcova, B.L. Mordike, Significance of stable and metastable phases in high temperature creep resistant magnesium-rare earth base alloys, J. Alloys Compd. 378 (2004) 196-201.

[31] M. Suzuki, T. Kimura, J. Koike, K. Maruyama, Effects of zinc on creep strength and deformation substructures in Mg-Y alloy, Mater. Sci. Eng. A 387-389 (2004) 706-709.

[32] J. Wang, N. Stanford, Investigation of precipitate hardening of slip and twinning in $\mathrm{Mg} 5 \% \mathrm{Zn}$ by micropillar compression, Acta Mater. 100 (2015) 53-63.

[33] J.J. Bhattacharyya, F.Wang, N. Stanford, S.R. Agnew, Slip mode dependency of dislocation shearing and looping of precipitates in Mg alloy WE43, Acta Mater. 146 (2018) 55-62.

[34] Y. Ivanishenko, W. Lojkowski, R.Z. Valiev, H.-J. Fecht, The mechanism of formation of nanostructure and dissolution of cementite in a pearlitic steel during high pressure torsion, Acta Mater. 51 (2003) 5555-5570.

[35] M. Cabibbo, E. Evangelista, M. Vedani, Influence of severe plastic deformations on secondary phase precipitation in a $6082 \mathrm{Al}-\mathrm{Mg}-\mathrm{Si}$ alloy, Metall. Mater. Trans A 36 A (2005) 1353-1364.

[36] M. Murayama, Z. Horita, K. Hono, Microstructure of two-phase Al-1.7 at\% $\mathrm{Cu}$ alloy deformed by equal channel angular pressing, Acta Mater. 49 (2001) 21-29.

[37] S. K. Panigrahi, R. Jayaganthan, Influence of solutes and second phase particles on work hardening behavior of Al 6063 alloy processed by cryorolling, Mater. Sci. Eng. A 528 (2011) 3147-3160.

[38] I.G. Urrutia, M. Morris, D.G. Morris, The effect of coarse second-phase particles and fine precipitates on microstructure refinement and mechanical properties of severely deformed Al alloy, Mater. Sci. Eng. A 394 (2005) 399-410.

[39] O.N. Senkov, F.H. Froes, V.V. Stolyarov, R.Z. Valiev, J. Liu, Microstructure and microhardness of an Al-Fe alloy subjected to severe plastic deformation and aging, Nanostruct. Mater. 10 (1998) 691-698.

[40] Z. Horita, K. Ohashi, T. Fujita, K. Kaneko, T.G. Langdon, Achieving high strength and high ductility in precipitation-hardened alloys, Adv. Mater. 17 (2005) 15991602.

[41] B. Yang, Y. T. Zhou, D. Chen, X. L. Ma, Local decomposition induced by dislocation motions inside precipitates in an Al-alloy, Sci. Rep. 3 (2013)1039-1044.

[42] Z. Liu, X. Chen, X. Han, Y. Gu, The dissolution behavior of $\theta^{\prime}$ phase in $\mathrm{Al}-\mathrm{Cu}$ binary alloy during equal channel angular pressing and multi-axial compression, Mater. Sci. Eng. A 527 (2010) 4300-4305.

[43] M.J. Starink, X. Cheng, S. Yang, Hardening of pure metals by high-pressure torsion: A physically based model employing volume-averaged defect evolutions, Acta Mater. 61 (2013) 183-192.

[44] H.J. Lee, S.K. Lee, K.H. Jung, G.A. Lee, B. Ahn, M. Kawasaki, T.G. Langdon, Evolution in hardness and texture of a ZK60A magnesium alloy processed by high-pressure torsion, Mater. Sci. Eng. A 630 (2015) 90-98. 
[45] H.J. Lee, B. Ahn, M. Kawasaki, T.G. Langdon, Evolution in hardness and microstructure of ZK60A magnesium alloy processed by high-pressure torsion, J. Mater. Res. Technol. 4 (2015) 18-25.

[46] O.B. Kulyasova, R.K. Islamgaliev, A.R. Kil'mametov, R.Z. Valiev, Superplastic behavior of magnesium-based $\mathrm{Mg}-10$ wt \% Gd alloy after severe plastic deformation by torsion, Phys. Met. Metallogr. 101 (2006) 585-590.

[47] M. Kai, Z. Horita, T.G. Langdon, Developing grain refinement and superplasticity in a magnesium alloy processed by high-pressure torsion, Mater. Sci. Eng. A 488 (2008) 117-124.

[48] Y. Huang, R.B. Figueiredo, T. Baudin, A.L. Helbert, F. Brisset, T.G. Langdon, Effect of temperature on the processing of a magnesium alloy by high-pressure torsion, $\mathrm{J}$. Mater. Sci. 47 (2012) 7796-7806.

[49] Y. Huang, R.B. Figueiredo, T. Baudin, F. Brisset, T.G. Langdon, Evolution of strength and homogeneity in a magnesium AZ31 alloy processed by high-pressure torsion at different temperatures, Adv. Eng. Mater. 14 (2012) 10181026.

[50] L.R.C. Malheiros, R.B. Figueiredo, T.G. Langdon, Grain size and microhardness evolution during annealing of a magnesium alloy processed by high-pressure torsion, J. Mater. Res. Technol. 4 (2015) 14-17.

[51] O.B. Kulyasova, R.K. Islamgaliev, Y.H. Zhao, R.Z. Valiev, Enhancement of themechanical properties of an $\mathrm{Mg}-$ $\mathrm{Zn}-\mathrm{Ca}$ alloy using high-pressure torsion, Adv. Eng. Mater. 17 (2015) 1738-1741.

[52] A. Singh, D.A. Basha, H. Somekawa, K. Tsuchiya, Nucleation of recrystallized magnesium grains over quasicrystalline phase during severe plastic deformation of a $\mathrm{Mg}-\mathrm{Zn}-\mathrm{Y}$ alloy at room temperature, Scr. Mater. 134 (2017) 80-84. 